\title{
Analysis of risk factors for mortality of in-hospital pneumonia patients in Bushulo Major Health Center, Hawassa, Southern Ethiopia
}

\author{
Zinabu Teka ${ }^{1}$, Ayele Taye ${ }^{2}$, Zemichael Gizaw $^{3}$ \\ ${ }^{1}$ Department of Statistics, University of Gondar, Gondar, Ethiopia \\ ${ }^{2}$ School of Mathematical and Statistical Sciences, Hawassa University, Hawassa, Ethiopia \\ ${ }^{3}$ Department of Environmental and Occupational Health and Safety, College of Medicine and Health Sciences, University of Gondar
}

\section{Email address:}

take.z70@gmail.com (Z.Teka), ayele_taye@yahoo.com(A. Taye), zemichael12@gmail.com (Z. Gizaw)

\section{To cite this article:}

Zinabu Teka, Ayele Taye, Zemichael Gizaw. Analysis of Risk Factors for Mortality of In-Hospital Pneumonia Patients in Bushulo Major Health Center, Hawassa, Southern Ethiopia. Science Journal of Public Health. Vol. 2, No. 5, 2014, pp. 373-377.

doi: 10.11648/j.sjph.20140205.11

\begin{abstract}
Background: Pneumonia remains a significant health problem in the world with significant morbidity and mortality. More than 1.16 million child pneumonia deaths occurred in just 15 countries (including Ethiopia, India at the first rank) in 2008, according to WHO figures. These 15 countries account for nearly three-quarters of all child pneumonia deaths worldwide. It is more likely in sub Saharan African countries. Objective: The aim of the present study was to analyze the risk factors of mortality of in-hospital patients due to pneumonia at Bushulo Major Health Center, Hawassa. Methods: Retrospective chart review of 431 patients was prepared for those hospitalized with pneumonia during January 2008 to December 2010. Both Bayesian and classical logistic regression models were applied for analyzing the data. Results: The logistic analysis revealed that the odds of being at risk to death due to pneumonia in-hospital was higher for patients with rural residence, diagnosed at wet season, having respiratory distress, with pneumonia complication, having vomiting, with short breathing problem and fast breathing problem, and long duration of the symptoms (disease). However, the risk was lower for patients with long time stay in-hospital and with 36-39 oC body temperature both at first and last diagnosis. Conclusion: Results revealed that the covariates: residence of a patient, whether or not a patient has vomiting, time from onset of symptoms to diagnosis (days), body temperature at first diagnosis (oC), body temperature at last diagnosis (oC), season when a patient diagnosed, pneumonia complications, total hospital stay (days), breathing problem and respiratory distress were significant predictors of discharge/death status of in-hospital pneumonia patients.
\end{abstract}

Keywords: Logistic Regression, Pneumonia, Bushulo, Hawassa

\section{Introduction}

Pneumonia is an inflammation of the lungs involving the alveolar ducts and alveolar sacs. It is associated with acute respiratory tract infection and recently developed radiological signs (Marston, 1997 and Andreoli, 1997). Pneumonia ranks $6^{\text {th }}$ among the causes of death in the world (Hasslett and Crompton, 1995). The pathogens causing pneumonia have not changed much over the years, but their relative importance has changed and there are regional differences (File et al., 1998). Clinicians need to be aware of the major organisms causing community- and hospital-acquired pneumonia, so that therapy may be started with the most cost-effective and appropriate antibiotics (File et al., 1998).

About 20\% with typical pneumonia require hospitalization. Those most at risk for developing complications are hospitalized. Elderly people are often hospitalized for pneumonia as there are many complications. Community acquired pneumonia (CAP) causes significant morbidity and mortality worldwide in elderly patients.

On $12^{\text {th }}$ November 2009, when the world marked the first World Pneumonia Day, the day was also marked in several countries of Africa including Ghana, Uganda, Kenya, DRC and Ethiopia under different themes (WHO, 2010). Although there are numerous papers dealing with causes of community acquired pneumonia and with the prognosis once the patients have been admitted to hospital, the literature concerning the 
identification of factors that make subjects prone to be died of pneumonia in hospital is sparse.

\section{Methodology}

\subsection{Study Population}

This study has reviewed pneumonia in-patients' card in Bushulo Major Health Center called locally "Loke", which is located at Hawassa city in SNNPR. Data were obtained from discharge/death records of all health admissions at Bushulo Major Health Center, Hawassa, between $1^{\text {st }}$ January 2008 to $31^{\text {st }}$ December 2010 .

\subsection{Sample Size Determination}

The statistical approaches for calculating overall and stratum sample sizes in a stratified random sample are fairly straight forward. The procedure is somewhat complicated with the incorporation of cost as well as the possibility of correlation among the stratum samples. Stratification can often be very effective with just a few strata; more strata lead to diminishing returns with greater effort. Actually, there were a total of 4314 patients in the sampling frame (total population size) with 2262 patient in urban residence $\left(\mathrm{N}_{1}\right)$ and 2052 in rural residence $\left(\mathrm{N}_{2}\right)$.

Thus, the sample size determination formula, adopted in this study for proportion was as follows (Cochran, 1977):

$$
n=\frac{\sum_{i=1}^{2} \frac{N_{i}^{2} p(1-p)}{W_{i}}}{\frac{N^{2} d^{2}}{\mathrm{Z}_{\alpha / 2}{ }^{2}}+N p(1-p)}
$$

where, $\mathrm{n}$ is the sample size required, $\mathrm{p}$ is the population proportion of mortality of pneumonia hospitalized patients, $\mathrm{Z}_{\alpha / 2}$ is Standard normal distribution that correspond to the level of confidence, $d$ is the absolute precision, $\mathrm{N}=\mathrm{N}_{1}+\mathrm{N}_{2}$ is total number of pneumonia patients, $\mathrm{N}_{\mathrm{i}}=$ the number of patients in i residence $\left(i=\right.$ urban, rural), $\mathrm{W}_{\mathrm{i}}=$ the proportion of $\mathrm{N}_{\mathrm{i}}$ to $\mathrm{N}$ (stratum weight).

Here, the total sample size was allocated to two strata with stratification of residence of patients. Proportional allocation to each of the strata was used. The present study used the estimated proportion of death $\mathrm{p}=0.156$ from Dagnew et. al. (2007), a statistical level of significance, $\alpha=$ 0.05 , an absolute precision of $d=0.0325$ (chosen based on time and cost), and 4314 of total in-hospitalized patients due to pneumonia (2262 from urban residence and 2052 from rural residence). Accordingly, n was found to be 431, and so far 431 in-hospital patients' (226 from urban and 205 from rural) charts were reviewed for data collection.

Actually, patient charts had been selected randomly based on computer generated system proportionally from the two strata (Urban and Rural).

\section{Results and Discussion}

\subsection{Descriptive Analysis Results}

In this study, a sample total of 431 patients of pneumonia were considered. Out of which $18.79 \%$ death cases occurred, and $81.21 \%$ were discharged. $47.56 \%$ of the patients were from rural areas and $52.44 \%$ from urban areas From the total patients, $54.06 \%$ were male patients and $45.94 \%$ female patients. Under five years old children took $64.27 \%$ of the total sample, while the age groups $5-14,15-$ 45 and greater than 45 years covered $10.44 \%, 11.6 \%$ and $13.69 \%$, respectively. $43.39 \%$ of the patients had vomiting and $56.61 \%$ with no vomiting. Regarding patients coughing status, $38.98 \%$ of the total patients had sever cough while $48.26 \%$ and $12.76 \%$ had mild and no cough, respectively.

Table 1. Summary Results and Test of Associations between Death/Discharge Status of Patients and Related Risk Factors (Bushulo Major Health Center, 2008-2010).

\begin{tabular}{|c|c|c|c|c|c|c|}
\hline Variable Name & Category & Number of Discharged (\%) & $\begin{array}{l}\text { Number of Death } \\
(\%)\end{array}$ & $\mathrm{N}$ out of $431(\%)$ & Chi-square (P-value) & LR (P-value) \\
\hline \multirow{2}{*}{ Patient's sex } & Female & $162(81.8)$ & $36(18.2)$ & $198(45.94)$ & \multirow{3}{*}{$\begin{array}{l}.090 \\
(.764)\end{array}$} & \multirow{3}{*}{$\begin{array}{l}.090 \\
(.764)\end{array}$} \\
\hline & Male & $188(80.7)$ & $45(19.3)$ & $233(54.06)$ & & \\
\hline \multirow{4}{*}{ Age of the patient } & $<5$ & $215(77.6)$ & $62(22.4)$ & $277(64.27)$ & & \\
\hline & $5-14$ & $40(88.9)$ & $5(11.1)$ & $45(10.44)$ & \multirow{3}{*}{$\begin{array}{l}8.027 \\
(.045)^{*}\end{array}$} & \multirow{3}{*}{$\begin{array}{l}8.993 \\
(.029)\end{array}$} \\
\hline & $15-45$ & $46(92.0)$ & $4(8.0)$ & $50(11.6)$ & & \\
\hline & $>45$ & $49(83.1)$ & $10(16.9)$ & $59(13.69)$ & & \\
\hline \multirow{2}{*}{ Residence of patient } & Urban & $198(87.6)$ & $28(12.4)$ & $226(52.44)$ & \multirow{2}{*}{$\begin{array}{l}12.769 \\
(.000)^{*}\end{array}$} & \multirow{2}{*}{$\begin{array}{r}12.883 \\
(.000)\end{array}$} \\
\hline & Rural & $152(74.1)$ & $53(25.9)$ & $205(47.56)$ & & \\
\hline \multirow{2}{*}{$\begin{array}{l}\text { Whether the patient } \\
\text { has vomiting }\end{array}$} & No & $209(85.7)$ & $35(14.3)$ & $244(56.61)$ & \multirow{2}{*}{$\begin{array}{l}7.295 \\
(.007)^{*}\end{array}$} & \multirow{2}{*}{$\begin{array}{l}7.234 \\
(.007)\end{array}$} \\
\hline & Yes & $141(75.4)$ & $46(24.6)$ & $187(43.39)$ & & \\
\hline \multirow{3}{*}{$\begin{array}{l}\text { Patient's coughing } \\
\text { status }\end{array}$} & None & $51(92.7)$ & $4(7.3)$ & $55(12.76)$ & \multirow{3}{*}{$\begin{array}{l}13.399 \\
(.001)^{*}\end{array}$} & \multirow{3}{*}{$\begin{array}{r}14.008 \\
(.001)\end{array}$} \\
\hline & Mild & $176(84.6)$ & $32(15.4)$ & $208(48.26)$ & & \\
\hline & Sever & $123(73.2)$ & $45(26.8)$ & $168(38.98)$ & & \\
\hline \multirow{3}{*}{$\begin{array}{l}\text { Time from onset of } \\
\text { symptoms to } \\
\text { diagnosis (days) }\end{array}$} & $<4$ & $123(86.6)$ & $19(13.4)$ & $142(32.95)$ & \multirow{3}{*}{$\begin{array}{l}13.650 \\
(.001)^{*}\end{array}$} & \multirow{3}{*}{$\begin{array}{r}12.966 \\
(.002)\end{array}$} \\
\hline & $4-7$ & $132(85.2)$ & $23(14.8)$ & $155(35.96)$ & & \\
\hline & $>7$ & $95(70.9)$ & $39(29.1)$ & $134(31.09)$ & & \\
\hline Variable Name & Category & Number of Discharged (\%) & $\begin{array}{l}\text { Number of Death } \\
(\%)\end{array}$ & $\mathrm{N}(\%$ out of 431$)$ & $\begin{array}{l}\text { Chi-square } \\
\text { (Sig.) }\end{array}$ & $\begin{array}{l}\text { LR } \\
\text { (Sig.) }\end{array}$ \\
\hline Body temperature at & $<36$ & $28(70.0)$ & $12(30.0)$ & $40(9.28)$ & 31.450 & 29.246 \\
\hline
\end{tabular}




\begin{tabular}{|c|c|c|c|c|c|c|}
\hline Variable Name & Category & Number of Discharged (\%) & $\begin{array}{l}\text { Number of Death } \\
\text { (\%) }\end{array}$ & $\mathrm{N}$ out of $431(\%)$ & Chi-square (P-value) & LR (P-value) \\
\hline \multirow[t]{2}{*}{ first diagnosis $\left({ }^{\circ} \mathrm{C}\right)$} & $36-39$ & $262(88.2)$ & $35(11.8)$ & 297(68.91) & \multirow[t]{2}{*}{$(.000)^{*}$} & \multirow[t]{2}{*}{$(.000)$} \\
\hline & $>39$ & $60(63.8)$ & $34(36.2)$ & $94(21.81)$ & & \\
\hline \multirow{3}{*}{$\begin{array}{l}\text { Body temperature at } \\
\text { last diagnosis }\left({ }^{\circ} \mathrm{C}\right)\end{array}$} & $<36$ & $29(61.7)$ & $18(38.3)$ & $47(10.9)$ & \multirow{3}{*}{$\begin{array}{r}117.891 \\
(.000)^{*}\end{array}$} & \multirow{3}{*}{$\begin{array}{r}101.43 \\
(.000)\end{array}$} \\
\hline & $36-39$ & $298(92.5)$ & $24(7.5)$ & $322(74.71)$ & & \\
\hline & $>39$ & $23(37.1)$ & $39(62.9)$ & $62(14.39)$ & & \\
\hline \multirow{4}{*}{$\begin{array}{l}\text { Season when the } \\
\text { patients diagnosed } \\
\text { Pneumonia } \\
\text { complications }\end{array}$} & Dry & $137(86.2)$ & $22(13.8)$ & $59(36.89)$ & \multirow{2}{*}{$\begin{array}{l}4.056 \\
(.044)^{*}\end{array}$} & \multirow{2}{*}{$\begin{array}{l}4.204 \\
(.040)\end{array}$} \\
\hline & Wet & $213(78.3)$ & $59(21.7)$ & $272(63.11)$ & & \\
\hline & No & $218(86.2)$ & $35(13.8)$ & 253(58.7) & 9.873 & 9.730 \\
\hline & Yes & $132(74.2)$ & $46(25.8)$ & $178(41.3)$ & $(.002)^{*}$ & $(.002)$ \\
\hline \multirow{2}{*}{$\begin{array}{l}\text { Severity of } \\
\text { pneumonia }\end{array}$} & Mild & $185(87.3)$ & $27(12.7)$ & $212(49.2)$ & \multirow{2}{*}{$\begin{array}{l}10.032 \\
(.002)^{*}\end{array}$} & \multirow{2}{*}{$\begin{array}{r}10.204 \\
(.001)\end{array}$} \\
\hline & Sever & $165(75.3)$ & $54(24.7)$ & $219(50.8)$ & & \\
\hline \multirow{3}{*}{$\begin{array}{l}\text { Total hospital stay } \\
\text { (days) }\end{array}$} & $<4$ & $59(62.8)$ & $35(37.2)$ & $94(21.81)$ & \multirow{3}{*}{$\begin{array}{l}27.091 \\
(.000)^{*}\end{array}$} & \multirow{3}{*}{$\begin{array}{r}24.184 \\
(.000)\end{array}$} \\
\hline & $4-5$ & $150(85.2)$ & $26(14.8)$ & $176(40.84)$ & & \\
\hline & $>5$ & 141(87.6) & $20(12.4)$ & 161(37.35) & & \\
\hline \multirow{3}{*}{ Breathing problem } & No & 199(91.3) & $19(8.7)$ & $218(50.58)$ & \multirow{3}{*}{$\begin{array}{c}29.520 \\
(.000)^{*}\end{array}$} & \multirow{3}{*}{$\begin{array}{r}30.710 \\
(.000)\end{array}$} \\
\hline & Short & $40(72.7)$ & $15(27.3)$ & $55(12.76)$ & & \\
\hline & Fast & $111(70.3)$ & $47(29.7)$ & $158(36.66)$ & & \\
\hline \multirow{3}{*}{ Respiratory distress } & No & $270(90.3)$ & $29(9.7)$ & 299(69.37) & \multirow{2}{*}{$\begin{array}{l}52.910 \\
(.000)^{*}\end{array}$} & \multirow{2}{*}{$\begin{array}{r}49.111 \\
(.000)\end{array}$} \\
\hline & Yes & $80(60.6)$ & $52(39.4)$ & $132(30.63)$ & & \\
\hline & CAF & $91(84.3)$ & $17(15.7)$ & $108(25.06)$ & \multirow{3}{*}{$\begin{array}{l}.959 \\
(.619)\end{array}$} & \multirow{3}{*}{$\begin{array}{l}.984 \\
(.611)\end{array}$} \\
\hline \multirow[t]{2}{*}{ Treatment taken } & Ampicillin & $40(81.6)$ & $9(18.4)$ & $49(11.37)$ & & \\
\hline & Combined & 219(79.9) & $55(20.1)$ & $274(63.57)$ & & \\
\hline
\end{tabular}

* significant $(\mathrm{P}$-value $<0.05)$

From all patients included in this study, the highest proportion $(35.96 \%)$ of them had been staying 4 to 7 days from onset of symptoms to diagnosis, followed by those who had been staying less than 4 days $(32.95 \%)$, while the lowest proportion $(31.09 \%)$ was of the patients whose duration of symptoms onset to diagnosis was more than 7 days. There was the highest proportion $(68.91 \%)$ of patients in cases whose body temperature at first diagnosis was 36$39^{\circ} \mathrm{C}$ while proportion of patients whose body temperature at first diagnosis was more than $39{ }^{\circ} \mathrm{C}$ and less than $36{ }^{\circ} \mathrm{C}$ were $21.81 \%$ and $9.28 \%$, respectively.

The results in Table 1 also revealed that the proportion of patients whose body temperature at last diagnosis was less than $36{ }^{\circ} \mathrm{C}$, between $36{ }^{\circ} \mathrm{C}$ and $39^{\circ} \mathrm{C}$, and greater than $39^{\circ} \mathrm{C}$ were $10.9 \%, 74.71 \%$ and $14.39 \%$ of the total sampled patients, respectively. Majority $(63.11 \%)$ of the total cases in the sample were diagnosed in wet season (April to September), whereas $36.89 \%$ in dry season (October to March). The proportion of patients with Pneumonia complications reported $41.3 \%$ and those without complication covered $58.7 \%$ of the total sample. $50.8 \%$ had sever pneumonia and $49.2 \%$ had mild Pneumonia. $21.81 \%$ of the patients had stay less than 4 days in hospital, whereas $40.84 \%$ and $37.35 \%$ had stay 4 to 5 and more than 5 days, respectively.

There were $12.76 \%$ of subjects with short breathing, $36.66 \%$ of subjects with fast breathing and $50.58 \%$ of patients with no breathing problem. $30.63 \%$ of the patients had a respiratory distress and $69.37 \%$ had no respiratory distress. Most (63.57\%) of the patients were given combined treatments, whereas $25.06 \%$ and $11.37 \%$ took $\mathrm{CAF}$ and Ampicillin, respectively.

In case of bivariate analysis, the chi-square test can be used to determine the association between discharge/death status of patients (outcome variable) and many independent variables (risk factors) separately. It is based on the difference between the expected frequencies and the observed frequencies in one or more categories in the frequency table.

Accordingly, there was a statistically significant association at $5 \%$ level of significance between the outcome variable (discharge/death status of patients) and the explanatory variables: age of a patient, residence of a patient, a patient with vomiting or not, patient's coughing status, time from onset of symptoms to diagnosis (days), body temperature at first diagnosis $\left({ }^{\circ} \mathrm{C}\right)$, body temperature at last diagnosis $\left({ }^{\circ} \mathrm{C}\right)$, season when the patients diagnosed, pneumonia complications, severity of pneumonia, total length of hospital stay (days), breathing problem and respiratory distress. However, the outcome variable was not significantly associated with patient's sex and treatment taken (Table 1 last 2 columns). Similarly, the same results were obtained using the likelihood ratio test.

\subsection{Multiple Logistic Regression Results}

\subsubsection{Testing Each Variable and Interpreting the Results}

The likelihood ratio test assesses the overall logistic model but does not tell us if particular independents are statistically significant. This can be done using the Wald statistic which is commonly used to test the significance of individual logistic regression coefficients for each independent variable (that is to test the null hypothesis in logistic regression that a particular logit (effect) coefficient is zero). Summarized results for these are presented below in Table 2. At $5 \%$ level of significance, the significant predictors of status of a pneumonia patient using the forward likelihood ratio method in multivariate logistic regression model were residence of a patient, whether or not a patient has vomiting, time from onset of symptoms to 
diagnosis (days), body temperature at first diagnosis $\left({ }^{\circ} \mathrm{C}\right)$, body temperature at last diagnosis $\left({ }^{\circ} \mathrm{C}\right)$, season when the patients diagnosed, pneumonia complications, total hospital stay (days), breathing problem and respiratory distress.

Table 2. Estimated Logit Coefficients, Estimated Standard errors, Wald Statistic Values and Estimated Odds ratios for the Fitted Logistic Regression Model in the Final Step (Bushulo Major Health, 2008-2010).

\begin{tabular}{|c|c|c|c|c|c|c|c|c|}
\hline \multirow{2}{*}{ Predictor Variables } & \multirow{2}{*}{$\hat{\beta}$} & \multirow{2}{*}{$\mathbf{S . E}(\hat{\beta})$} & \multirow{2}{*}{ Wald } & \multirow{2}{*}{ Df } & \multirow{2}{*}{ P-value } & \multirow{2}{*}{$\operatorname{Exp}(\hat{\beta})$} & \multicolumn{2}{|c|}{ 95.0\% C.I. for $\operatorname{Exp}(\hat{\beta})$} \\
\hline & & & & & & & Lower & Upper \\
\hline \multicolumn{9}{|l|}{ Residence } \\
\hline $\begin{array}{l}\text { Rural } \\
\text { Vomiting } \\
\text { No(ref) }\end{array}$ & .802 & .399 & 4.030 & 1 & $.045^{*}$ & 2.229 & 1.019 & 4.877 \\
\hline Yes & .875 & .383 & 5.226 & 1 & $.022 *$ & 2.398 & 1.133 & 5.077 \\
\hline $\begin{array}{l}\text { Time from symptoms onset to diagnosis } \\
<4 \text { (ref) }\end{array}$ & & & 14.260 & 2 & $.001 *$ & & & \\
\hline $4-7$ & .384 & .509 & .569 & 1 & .451 & 1.468 & .542 & 3.977 \\
\hline$>7$ & 1.757 & .512 & 11.772 & 1 & $.001 *$ & 5.796 & 2.124 & 15.814 \\
\hline $\begin{array}{l}\text { Body temperature at first diagnosis } \\
<36^{\circ} \mathrm{C} \text { (ref) }\end{array}$ & & & 20.820 & 2 & $.000 *$ & & & \\
\hline $36-39^{\circ} \mathrm{C}$ & -1.637 & .574 & 8.128 & 1 & $.004 *$ & .195 & .063 & .600 \\
\hline$>39^{\circ} \mathrm{C}$ & .360 & .621 & .337 & 1 & .562 & 1.434 & .425 & 4.842 \\
\hline $\begin{array}{l}\text { Body temperature at last diagnosis } \\
<36^{\circ} \mathrm{C} \text { (ref) }\end{array}$ & & & 40.002 & 2 & $.000 *$ & & & \\
\hline $36-39^{\circ} \mathrm{C}$ & -1.933 & .515 & 14.063 & 1 & $.000 *$ & .145 & .053 & .397 \\
\hline$>39^{\circ} \mathrm{C}$ & .803 & .576 & 1.945 & 1 & .163 & 2.232 & .722 & 6.895 \\
\hline \multicolumn{9}{|l|}{ Season } \\
\hline Wet & .868 & .406 & 4.584 & 1 & $.032 *$ & 2.383 & 1.076 & 5.276 \\
\hline \multicolumn{9}{|l|}{ Pneumonia complications } \\
\hline Yes & 1.049 & .398 & 6.937 & 1 & $.008^{*}$ & 2.853 & 1.308 & 6.226 \\
\hline $\begin{array}{l}\text { Total length in-hospital stay } \\
<4 \text { (ref) }\end{array}$ & & & 7.926 & 2 & $.019 *$ & & & \\
\hline $4-5$ & -1.270 & .483 & 6.920 & 1 & $.009 *$ & .281 & .109 & .723 \\
\hline$>5$ & -1.174 & .515 & 5.195 & 1 & $.023 *$ & .309 & .113 & .848 \\
\hline $\begin{array}{l}\text { Breathing problem } \\
\text { No(ref) }\end{array}$ & & & 19.434 & 2 & $.000 *$ & & & \\
\hline Short & 1.288 & .593 & 4.722 & 1 & $.030 *$ & 3.627 & 1.135 & 11.593 \\
\hline Fast & 1.986 & .452 & 19.286 & 1 & $.000^{*}$ & 7.285 & 3.003 & 17.673 \\
\hline \multicolumn{9}{|l|}{ Respiratory distress } \\
\hline Yes & 1.531 & .399 & 14.752 & 1 & $.000 *$ & 4.621 & 2.116 & 10.091 \\
\hline Constant & -3.123 & .836 & 13.942 & 1 & $.000 *$ & .044 & & \\
\hline
\end{tabular}

* Significant (P-value < 0.05), Df: Degree of freedom, ref: reference category

Since the probability of the Wald statistics for each of the above 10 variables was less than the level of significance 0.05 , we mainly focus on the categories of these variables. Thus, one can interpret the effects of each covariate using the estimated odds ratio given in Table 2. The probability of the Wald statistic for the covariate rural residence was 0.045 , less than the level of significance 0.05 . Hence, the null hypothesis that the logit coefficient for rural residence was equal to zero was rejected. This supports the relationship that being discharged or death of Pneumonia hospitalized patient was associated with the covariate of patient's residence. And the value of $\operatorname{Exp}(\hat{\beta})$ was 2.229 which implied that the odds of being at risk to death of the pneumonia patient who resided in rural was 2.229 times more likely than those residing in urban. This might be due to the fact that rural residents had different life style than those of urban residents. Although health services do not have to be identical in the two settings, quality services appropriate for the needs of rural communities are

\section{imperative.}

The results in Table 2 also revealed that death risk was 2.383 times higher for those patients who were diagnosed in wet season than those who were diagnosed in dry season. The Wald criterion also demonstrated that the explanatory variable pneumonia complication made a significant contribution to discharge or death status of hospitalized patients $(\mathrm{P}$-value $=0.008)$.

\subsection{Discussion}

This study applies the Classical techniques to analyze risk factors of mortality due to Pneumonia. Logistic regression models have been used to have an in-depth understanding of factors associated with the probability of dying of a patient due to Pneumonia in-hospital. A number of variables were used to explain the variation in the discharge/death status of pneumonia patients.

During the period of this study, the epidemic strain of 
pneumonia caused severe illness and resulted in death of $18.79 \%$ of patients in the sample. Similar studies had found different results, for example, $42.6 \%$ in Chia-Cheng et al. (2009), 23.8\% in Kuo-Tung et al. (2010), and 14.7\% in Cui et al. (2010). In this study, almost $64.3 \%$ of the hospitalizations due to pneumonia involved individuals who were less than the age of 5 years old.

In the present study, discharge/death status of hospitalized patients due to pneumonia was not associated with patient's sex $(\mathrm{P}$-value $=0.764)$. This result was similar to the findings of Kuo-Tung et al. (2010). Similarly, there was an equality of discharge/death status in hospital patients with regard to treatments given $(\mathrm{P}$-value $=0.619)$. Patients who took different treatment (as per the prescription of the physician) including combined treatments were not significantly different to be discharged or died in hospital. The reason for this is not vivid but it might be due to the proper use of all prescribed antibiotics. Thus, if all patients use all treatments properly, they can benefit them equally.

Severity of pneumonia was significantly associated with health status of the patients. This might be due to the reason that sever pneumonia was significantly associated with greater risk of treatment failure. The early treatment failure was the cause of higher mortality. This result also coincides with previous study in Spain by Menendez et al. (2004).

Patients who had vomiting were more likely being at risk of death in-hospital than patients with no vomiting. The odds of death risk were higher in patients both with short and fast breathing problem than those patients without breathing problem $(\mathrm{OR}=2.398$, Table 2$)$. This may be due to the fact that breathing is the most vital function for maintenance of life.

\section{Conclusions}

Results revealed that the covariates: residence of a patient, whether or not a patient has vomiting, time from onset of symptoms to diagnosis (days), body temperature at first diagnosis $\left({ }^{\circ} \mathrm{C}\right)$, body temperature at last diagnosis $\left({ }^{\circ} \mathrm{C}\right)$, season when a patient diagnosed, pneumonia complications, total hospital stay (days), breathing problem and respiratory distress were significant predictors of discharge/death status of in-hospital pneumonia patients.

\section{Recommendations}

The risk of dying due to pneumonia was higher in rural individuals than the urban dwellers. According to the grapevine, scaling up of interventions such as health promotions on appropriate and effective treatment in home or community based care should be emphasized in rural areas to minimize the risk. And the awareness of early treatment in rural areas should be expanded via health extension workers, clinicians or any concerned body in collaboration with governmental and non-governmental organizations as creating healthy citizens is a duty of every one.

Strength and limitation of the study

Limitation of the study

- Due to its retrospectiveness, important variables were not included.

- $\quad$ Strength of the study

- In this study, we have investigated the contemporary phenomenon within the real-life context.

- $\quad$ This study is vigorously investigated the infrequent occurred cases within three years.

\section{List of Abbreviations}
CAP Community Acquired Pneumonia
DIC Deviance Information Criteria
DRC Democratic Republic of Congo
MCMC Markov Chain Monte Carlo
OR Odds Ratio
SNNPR Southern Nations Nationalities and People's Region
WHO World Health Organization

\section{References}

[1] Andreoli F. (1997). Infections of the Lower Tract. Cecil Essentials of medicine ( $4^{\text {th }}$ ed.) Pennsylvania, WB Sanders, 1997:699-707.

[2] Brooks, S. and Gelman, A. (1998). Alternative Methods for Monitoring Convergence of Iterative Simulations, Journal of Computational and Graphical Statistics 7, 434455.

[3] Cochran, W. G. (1977). Sampling Techniques ( $3^{\text {rd }}$ ed.). New York: John Wiley \& Sons.

[4] Dagnew M., Damte S., Daniel B.(2007). Analysis of Admissions to the Pediatric Emergency ward of Tikur Anbessa Hospital in Addis Ababa, Ethiopia. Ethiopian Journal of Health Development 21(1):48-52

[5] File TM J, Tan J, Plouffe J. (1998). The role of Atypical Pathogens: Mycoplasma Pneumonia, Chlamydia Pneumoniae, and Legionella Pneumophila in Respiratory Infection. Infectious disease clinics of North America 1998; 12: $569-592$.

[6] Gelman, A. and Rubin, D. (1992). Inference from Iterative Simulation using Multiple Sequences, Statistical Science 7, 457-511.

[7] Hasslett C., Crompton G.(1995). Diseases of the Respiratory System: Davidson's principles and practice of medicine, $7^{\text {th }}$ ed. New York, Churchill Livingston, 348-58.

[8] World Health Organization (2008). Global Action Plan for the Prevention and Control of Pneumonia (GAPP): Report of an Informal Consultation: La Mainaz, Gex, France, 5-7 March 2007 / Shamim Qazi, Martin Weber, Cynthia BoschiPinto, Thomas Cherian. 